\title{
3D reconstruction of a shallow archaeological site from high-resolution acoustic imagery: The Grace Dieu
}

\author{
R.M.K. Plets ${ }^{\mathrm{a}, \mathrm{c}, *}$, J.K. Dix ${ }^{\mathrm{a}, \mathrm{b}, \mathrm{c}}$, J.R. Adams ${ }^{\mathrm{b}}$, A.I. Best ${ }^{\mathrm{c}}$ \\ ${ }^{a}$ School of Ocean and Earth Science, University of Southampton, Southampton, UK \\ ${ }^{\mathrm{b}}$ Department of Archaeology, University of Southampton, Southampton, UK \\ ${ }^{\mathrm{c}}$ National Oceanography Centre, Southampton, UK
}

Received 17 February 2006; received in revised form 5 March 2007; accepted 7 April 2007

\begin{abstract}
Acoustic imaging and characterisation of buried objects (and in particular archaeological materials) in shallow-water $(<5 \mathrm{~m})$ is often unsuccessful owing to problems related to vessel-induced bubble turbulence and the restricted acoustic geometry of the system. A $2 \mathrm{D}$ surveying method that tackles these problems has been tested on the known wreck of the Grace Dieu (1418), Henry V's flagship, currently buried within the inter-tidal sediments of the Hamble River. The wooden hull is recognisable in the seismic sections as a high amplitude anomaly underlain by an acoustic blanking zone. Close survey line spacing (ca. $1 \mathrm{~m}$ ) allowed the construction of time slices, identifying the ovate plan of the hull. High, predominantly negative, reflection coefficients suggest this anomaly corresponds to degraded oak timbers buried within the sediment. Combining the data enabled the construction of a (pseudo)-3D image, revealing the dimensions and shape of the hull remains for the first time.
\end{abstract}

(C) 2007 Elsevier Ltd. All rights reserved.

Keywords: Maritime archaeology; Chirp; Shallow water; Buried wood

\section{Introduction}

For decades high-resolution acoustic sub-bottom profilers (Boomer, Pinger, Sparker, Chirp) have been used extensively in many sectors of the marine surveying community for Quaternary geological studies, habitat mapping, engineering, archaeology, resource prospection and environmental assessments (e.g. [1-5]). However, high-resolution marine acoustic surveying for buried objects in the shallow waters of the inter-tidal to immediate sub-tidal zone is still a major challenge. This is a consequence of a number of issues including the relationship between water depth and acoustic acquisition geometry; the problem of dissipating vessel-induced bubble clouds that significantly reduce the

\footnotetext{
* Corresponding author. Address: School of Ocean and Earth Sciences, National Oceanography Centre, Southampton, European Way, Southampton SO14 3ZH, UK. Tel.: +44 02380 596544; fax: +44 02380596554

E-mail address: rmkp@noc.soton.ac.uk (R.M.K. Plets).
}

signal-to-noise (SNR) ratio; and the necessity for high spatial survey accuracy in three-dimensions.

The challenge of these marginal environments is particularly acute for the maritime archaeological community, especially in cases where in situ preservation is preferred to excavation. Current best practice frequently requires archaeologists to investigate shallow-water $(<5 \mathrm{~m})$ sites non-destructively using terrestrial and/or marine methods. Although two-dimensional imaging of buried archaeological sites has successfully been accomplished in deeper water $[6,7]$, it is essential that methods are developed which are reliable in shallow water and which go beyond imaging. Further, if these cost-effective acoustic methods, which leave potential sites undisturbed, are to become an alternative to extensive archaeological excavations, then effective three-dimensional reconstructions and target characterisation have to become an essential part of the data analysis. These archaeological requirements are also increasingly echoed by the industrial sector and the military who rou- 
tinely use acoustic methods for accurate object detection (e.g. buried pipelines and debris) $[8,9]$.

This paper results from a combined marine archaeological and geophysical survey, undertaken in order to test survey and processing methods specifically adapted to operate in these extreme environments. The chosen survey site for this approach was the wreck of Henry V's flagship the Grace Dieu (1418), the fourth and last of the great ships built for Henry V (1387-1422; r. 1413-1422) [10]. Although built as a warship, she never saw action and by 1420 was in reserve at her berth in the Hamble River, UK (Fig. 1a). Furthermore, the Grace Dieu was the largest vessel ever built in England, up to that time, and, indeed, no bigger ship was built for another two hundred years. As such, she represented the acme of Tudor shipbuilding technology. As a consequence of this, the vessel was used as a venue for summits with visiting foreign dignitaries so they could marvel at the technological prowess of Henry's Navy. Eventually, in 1439, the Grace Dieu burnt down to the waterline after being struck by lightning and, after all usable materials were salvaged, she sunk at her berth in the Hamble River [10].

Even though the wreck site had been identified as early as 1850 , it was not until 1993 that the first site plan was published [11]. This plan (Fig. 1b), the result of several field seasons of terrestrial and underwater diver surveys, shows marginal timbers protruding a few centimetres from the mud, the location of test trenches and evidence, derived from probe surveys, of timbers buried less than $0.5 \mathrm{~m}$ below the seabed. Today, the remains of the wreck are still buried within muddy inter-tidal sediments, covered by 2 $5 \mathrm{~m}$ of water and only at exceptionally low tides, during the spring equinox, are a few of the marginal timbers exposed.

Burial of the wreck means that these previous investigations were limited in terms of the amount of information they provided. In particular the dimensions and shape of the deeper buried structure and the way it relates to the limited number of exposed known timbers is still poorly understood. The aim of this study is therefore threefold: firstly, to demonstrate the potential of acoustic sources in shallow water through detection and imaging of a buried wooden hull whose approximate position is known; secondly, to study the material properties of the remaining buried hull through the analysis of the acoustic properties of the image; and thirdly, to create a $3 \mathrm{D}$ reconstruction from which our knowledge of the vessel's dimensions and form can be increased.

\section{Method}

\subsection{Survey and data collection}

The marine survey was conducted using a square quadratic array of four baffled Chirp transducers (with a radius of $6 \mathrm{~cm}$ and a separation of $18.3 \mathrm{~cm}$ between the centre points of adjacent transducers) and a single channel receiver array consisting of a group of eight hydrophone elements. The source and receiver were mounted on a catamaran along with a co-located DGPS system, allowing navigational accuracy to within $\pm 1 \mathrm{~m}$ (Fig. 2). The Chirp sub-bottom profiler transmitted a $16 \mathrm{~ms}, 1.5-11.5 \mathrm{kHz}$ linearly swept pulse, shaped with a Blackmann-Harris envelope (Figs. 3a-d) at a rate of 8 pulses per second. Modelling experiments have demonstrated that the theoretical vertical resolution for this sweep, with a $-3 \mathrm{~dB}$ bandwidth of $3.47 \mathrm{kHz}$, is $0.32 \mathrm{~ms}$ two-way time (TWT) (ca. $24 \mathrm{~cm}$ using an approximate velocity conversion of $1500 \mathrm{~m} / \mathrm{s}$ ). Schock et al. [12] state that the beam pattern of a Chirp sweep depends on the main lobe and sidelobes of the autocorrelation of that sweep. They conclude that the sidelobe structure and effective aperture of a Chirp signal can be described through a single frequency beam pattern at the centre frequency of the Chirp sweep. On this assumption, the half-beamwidth (i.e. the angle between the vertical axis of the transducer array and the position where the pressure is $70.7 \%$ of the maximum value) of this array is calculated to be $26^{\circ}$, based on the far-field directivity function for an array [13] with a centre frequency of $6.66 \mathrm{kHz}$. Furthermore, the sidelobes of the sonar beam,
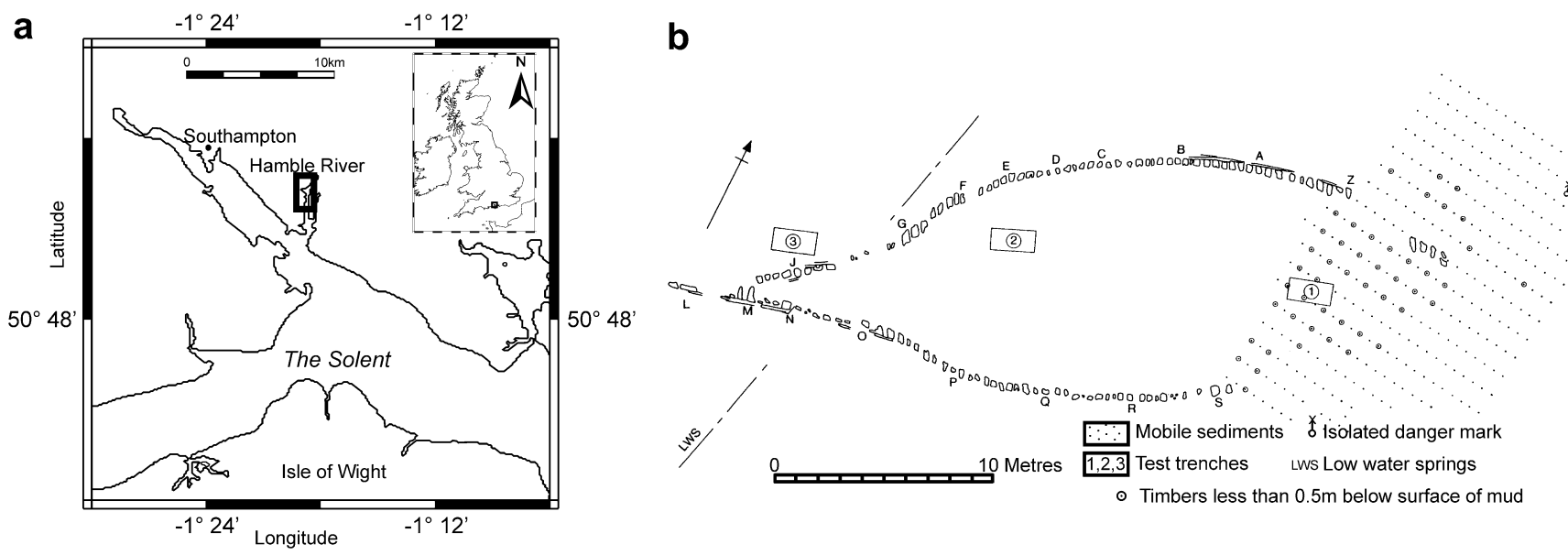

Fig. 1. (a) Location of the shipwreck site and (b) published site plan [11]. 


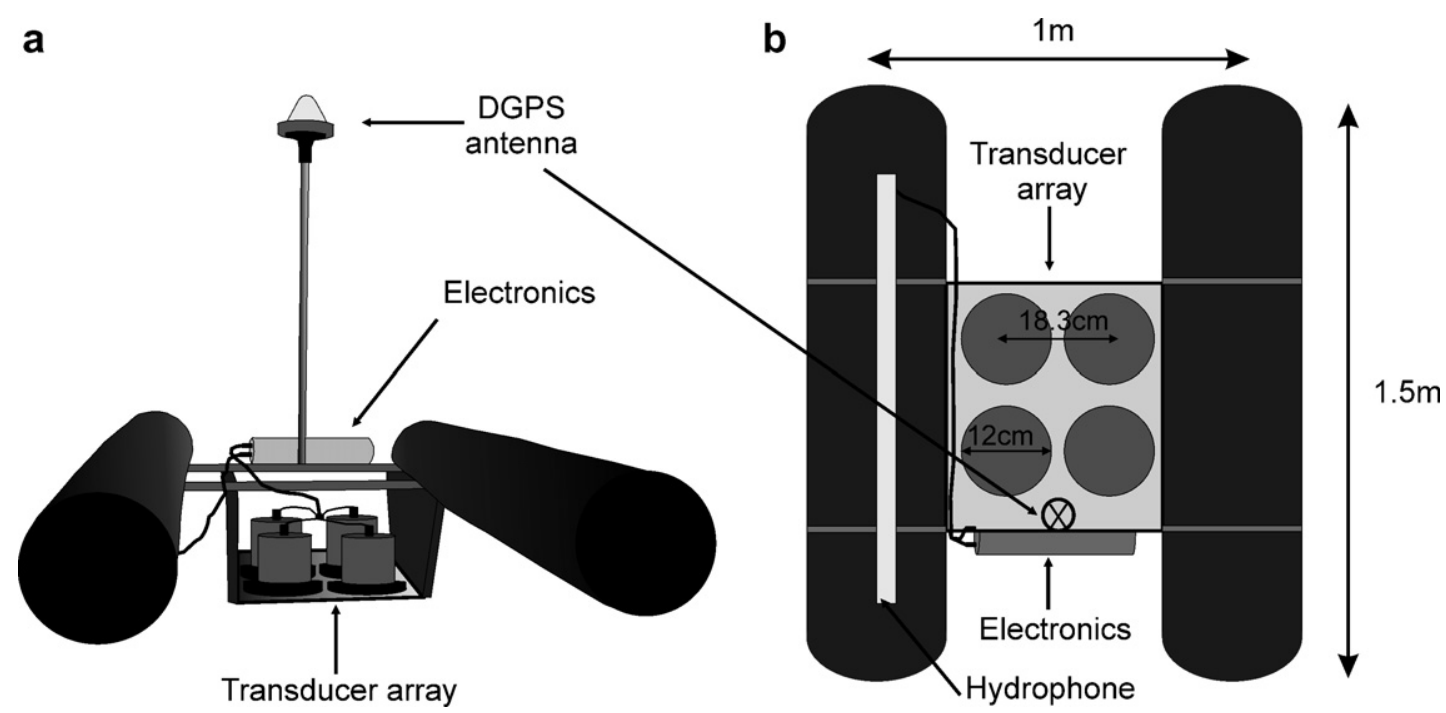

Fig. 2. Survey equipment configuration. (a) Side view of the transducer array mounted on the catamaran, with a co-located DGPS system. (b) Underside of the catamaran showing the position of the hydrophone streamer.
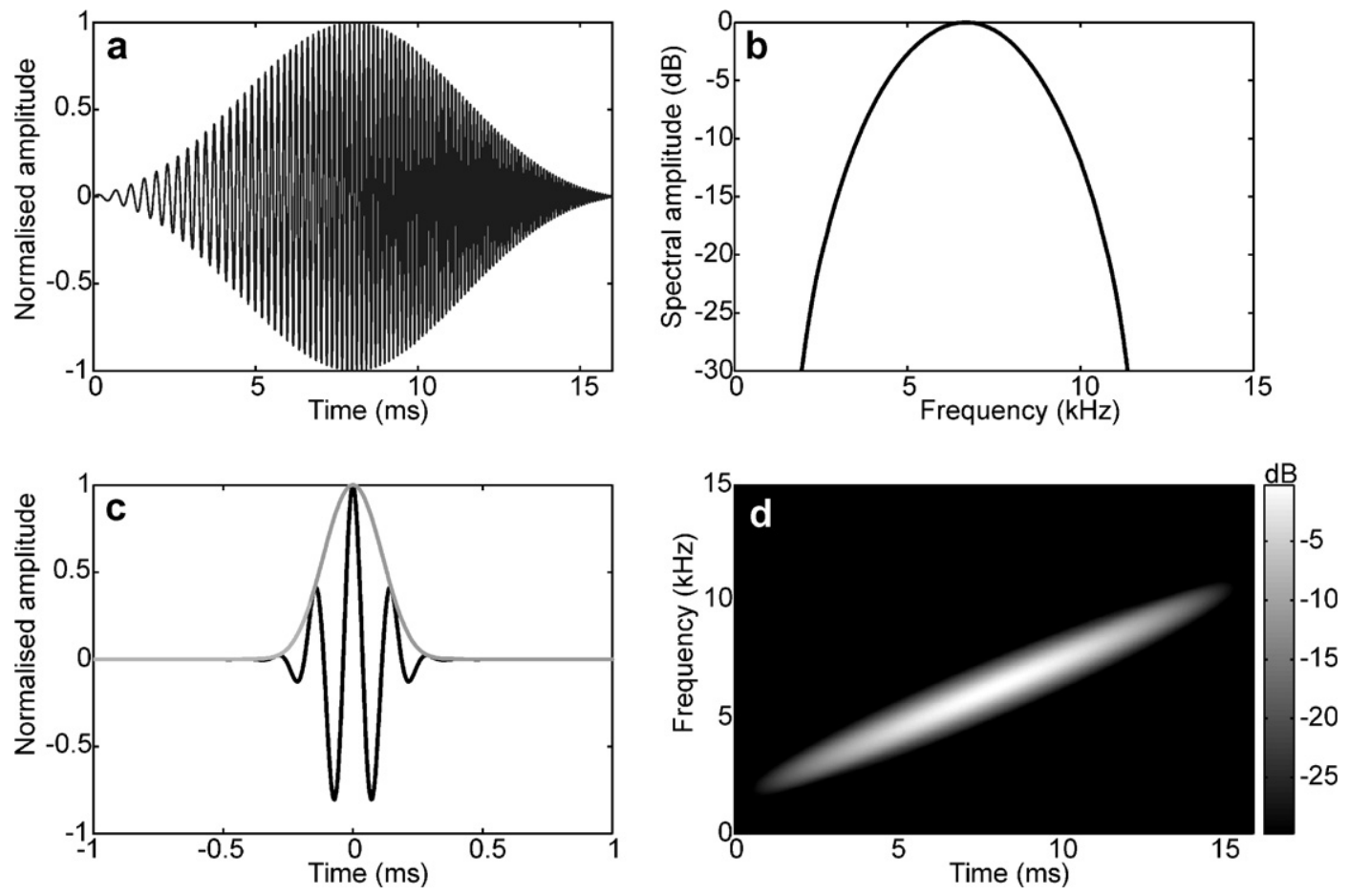

Fig. 3. Source sweep. (a) Time domain representation showing Blackmann-Harris sweep. (b) Power spectrum of 1.5-11.5 kHz pulse. (c) Klauder wavelet, the normalised auto-correlation function of the sweep, with its envelope. (d) Spectogram showing linear frequency function (dB scale).

produced by the array with a centre frequency of $6.66 \mathrm{kHz}$, have a maximum pressure which equals $58 \%$ of the maximum value of the main lobe and have a direction $90^{\circ}$ to the main lobe. Consequently, as a result of this horizontal directivity, the interference effect of the sidelobes on the data was considered to be minimal. Based on these figures, the minimum theoretical horizontal resolution, which is determined by the footprint of the main lobe on the riverbed, can be shown to vary between $2.0 \mathrm{~m}$ and $4.9 \mathrm{~m}$ for water depths ranging from 2 to $5 \mathrm{~m}$, respectively.
Two problems are generally encountered when using traditional surveying methods in exceptionally shallow water (i.e. an acoustic source towed behind a motorised survey vessel and a hydrophone unit offset approximately $2 \mathrm{~m}$ behind the source). Firstly, the angle between the incident and reflected ray increases as the water depth decreases. As a consequence, it can no longer be assumed that the angle of incidence is normal in very shallow water. Secondly, bubbles created by the survey vessel's propellers are unable to dissipate owing to the shallow tidal wedge, 
resulting in extensive acoustic blanking in the water column. In order to resolve these two problems, the traditional surveying method was adapted to increase the signal-to-noise ratio (SNR). First of all, the system was effectively made monostatic by mounting the hydrophone adjacent to the source (Fig. 2), assuring normal incidence and reducing the recording of possible off-axis features. Secondly, bubble turbulence in the water column was avoided through a non-motorised deployment: the catamaran was moved over the site by divers, from a survey vessel anchored upstream of the target. Further, the co-location of the real-time differential global positioning system (DGPS) and source/receiver platform enabled a controlled and guided survey to be undertaken. Within two hours of marine surveying, a dataset of 39 Chirp lines was acquired over the wreck site, resulting in a total of ca. $1250 \mathrm{~m}$ of acoustic data over an area of $1800 \mathrm{~m}^{2}$, with an average shot point spacing of $4 \mathrm{~cm}$ and an average line spacing of $1.1 \mathrm{~m}$.

In order to create an accurate basemap, for use in planning the acoustic survey, the surviving timbers protruding from the mud were surveyed with a terrestrial real time kinematic (RTK) - global positioning system (GPS). These timbers were exposed and accessible during the exceptionally low tides of the 2005 spring equinox. For an accurate terrestrial RTK survey to be undertaken it was necessary to establish a temporary GPS base station overlooking the wreck site. After $4 \mathrm{~h}$ of static logging, an accurate
$(<0.02 \mathrm{~m})$ position of the base station was obtained by processing its logged position against permanent, known, GPS receiver locations in the European terrestrial reference system (ETRS89). Once established, the data at the base station were logged simultaneously with data from a roving GPS antenna that was placed on each of the exposed timbers. By calculating baseline offsets, using Leica Geo Office post-processing software, it was then possible to obtain an OSGB36 (British National Grid) coordinate for the rover positions. This method provided a relative positional accuracy of approximately $\pm 0.02 \mathrm{~m}$ for the timbers. These data were also used to georectify a scanned image of the extant survey plan [11] using ArcView Geographic Information System (GIS) software, providing the accurate basemap as well as absolute timber positions for comparison with the marine geophysical data (Fig. 4).

\subsection{Acoustic data processing}

The Chirp data were collected in an uncorrelated format, recorded at a $25 \mathrm{kHz}$ sample frequency, which is sufficient to avoid frequency aliasing. All data processing was undertaken using PROMAX seismic processing software. After integrating the navigational data with time synchronised acoustic data and applying tidal corrections, using tidal data from the nearest tide gauge (Calshot), a simple processing flow was applied. This included: (1)

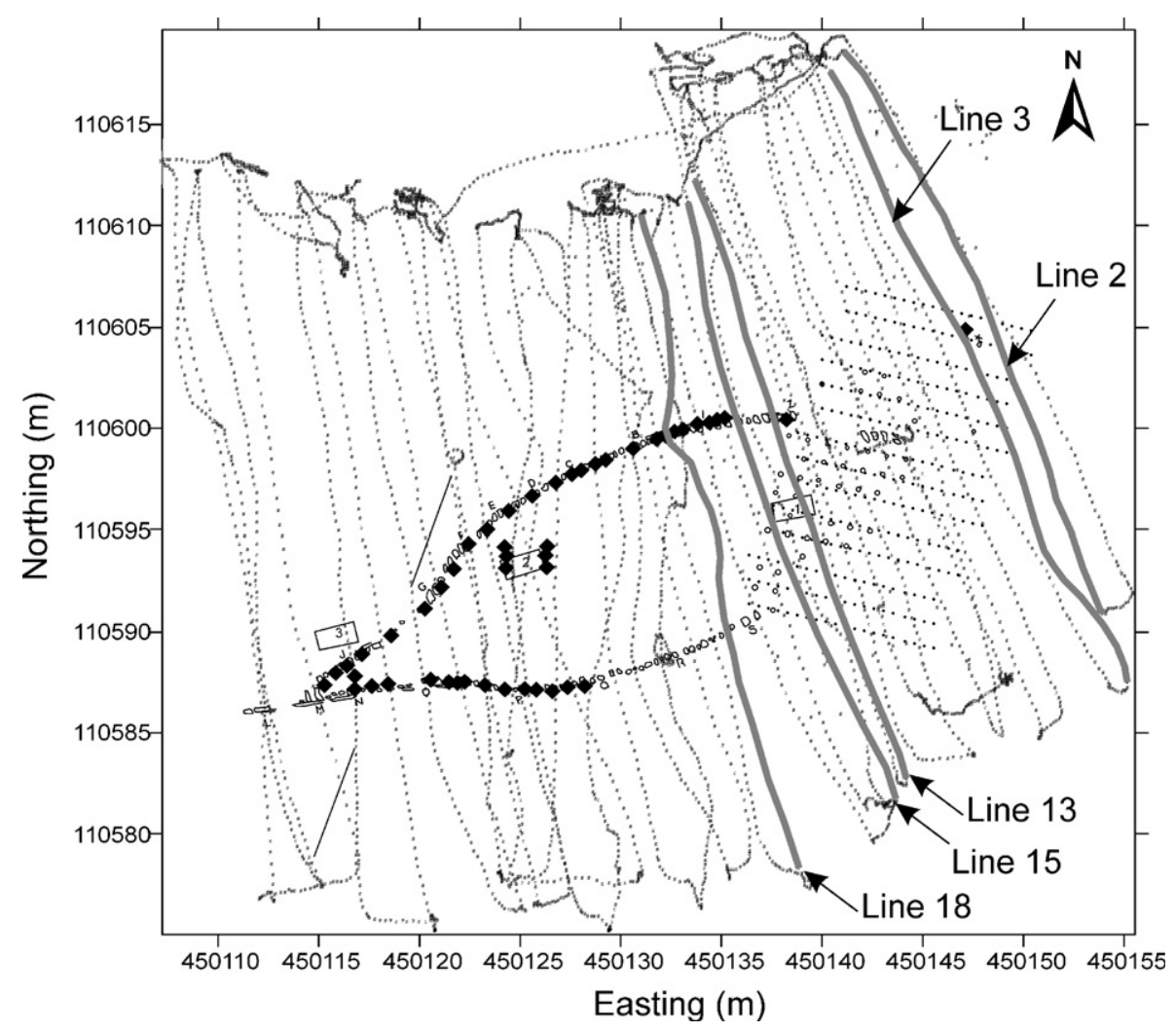

Fig. 4. Result of terrestrial RTK survey ( ), used to georectify site plan [11] and calibrate the marine acoustic data. Dotted lines represent the track lines and Chirp lines discussed in this paper are indicated with a grey line. The coordinate system used for all maps is Ordnance Survey Great Britain 1936 (OSGB36). 
'Cross-correlation' by which the raw data are correlated with a replica of the initial Chirp sweep, thus improving the signal-to-noise ratio of the Chirp data, (2) 'Automatic gain control' to vary the gain down the seismic section, and (3) 'Trace math transform (reflection strength)' to calculate the instantaneous amplitude which is defined as the amplitude of the complex Hilbert transform.

\subsection{Data interpretation}

For the visualisation and interpretation of the 2D data, Kingdom Suite software was used. In the first instance, the riverbed was selected manually (picked) from the processed seismic data and used to horizon flatten the data. Subsequently, time slices were taken parallel to the flattened riverbed, at regular $0.1 \mathrm{~ms}$ two-way time (TWT) $(\mathrm{ca} .7 .6 \mathrm{~cm})$ intervals, from which amplitude values were extracted. A natural neighbour gridding method with an increment of $0.5 \mathrm{~m}$ in the $x$ - and $y$-direction was then used to interpolate the amplitude data between the acoustic lines.
Subsequently, in an attempt to characterise features recognised within the shipwreck site on the processed data, reflection coefficients were calculated from the correlated data. The reflection coefficient $(R C)$ is a numerical way to express the effect of an interface between two materials and can be related to their physical properties. The technique used in this study to calculate reflection coefficients from normal incidence acoustic data was derived from a method to calculate absolute reflection coefficients described by Warner [14]. Re-working of Warner's approach enabled reflection coefficient of a deeper reflector $\left(R C_{\mathrm{DR}}\right)$ to be expressed as (see Appendix $\mathrm{A}$ for the full derivation):

$R C_{\mathrm{DR}}=\frac{A_{\mathrm{DR}} \cdot\left[v_{\mathrm{w}} \cdot\left(T W T_{\mathrm{p}} / 2\right)+\overline{v_{\mathrm{DR}}} \cdot\left(T W T_{\mathrm{DR}}-T W T_{\mathrm{p}}\right) / 2\right]}{x}$,

with $A_{\mathrm{DR}}$ the amplitude of the deeper reflector, $v_{\mathrm{w}}$ the velocity of sound through water, $\overline{v_{\mathrm{DR}}}$ the interval velocity or the velocity of sound through the sediments, $T W T_{\mathrm{p}}$

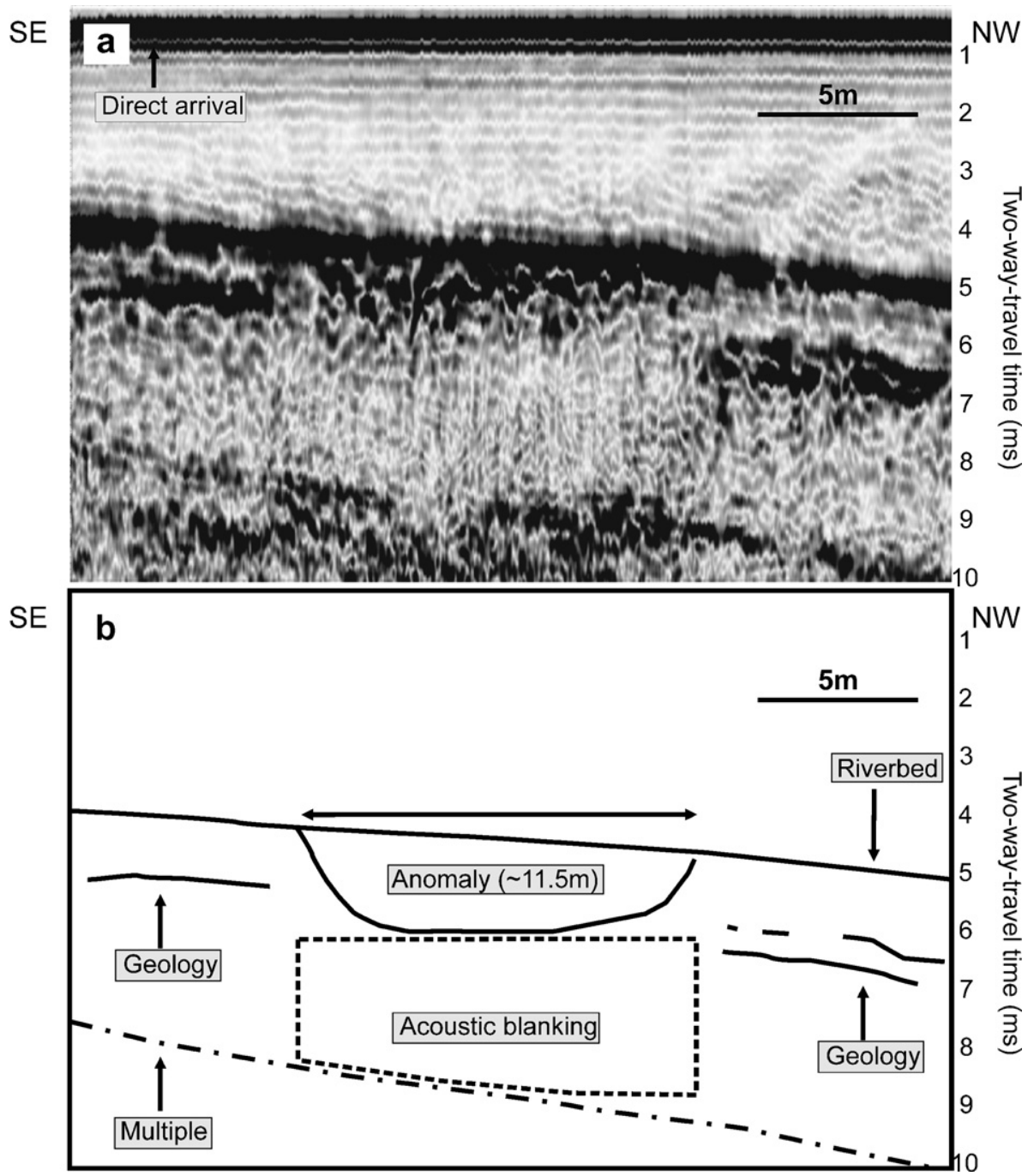

Fig. 5. Typical 2D Chirp profile acquired over the wreck site (Line 15 indicated in Fig. 4). (a) Original data, and (b) seismic interpretation. 
and $T W T_{\mathrm{DR}}$ the two-way-travel time to the riverbed and deeper reflector, respectively, and $x$ a calibration factor (see (A.10b)). In order to calculate the reflection coefficient using the method described above, the amplitude data of the raw correlated data were extracted using the following method: the positive and negative peaks, directly adjacent to the time slices were exported with their corresponding TWT and the largest absolute peak was used to compute the reflection coefficient.

Finally, features observed on the amplitude maps were identified and compared with features on the individual cross-sectional Chirp lines. This combined interpretation process enabled the picking of the acoustic anomaly associated with the hull remains of the Grace Dieu. These individual picks were then combined to reconstruct a full (pseudo-) 3D image of the vessel. Finally, the two-way travel time data was converted to depth on the basis of a water velocity of $1484 \mathrm{~m} / \mathrm{s}$ (velocity of salty water at $10^{\circ} \mathrm{C}$ and 30 ppt [15]) and a sediment velocity of $1517 \mathrm{~m} / \mathrm{s}$ (calculated from quadratic regression equations for a mean grain size of $4.7 \phi[16]$, the mean grain size values being obtained from particle size analysis of sediment samples acquired adjacent to the site).

\section{Results and discussion}

\subsection{Seismic data}

A typical Chirp acoustic profile can be seen in Fig. 5. On a number of Chirp sections, a high amplitude acoustic anomaly is recognisable within a $2.5 \mathrm{~ms}$ TWT window beneath the riverbed. The anomaly truncates sub-horizontal reflectors which are interpreted as being associated with the local geology, and is underlain by a distinct acoustic blanking zone.

The amplitude maps proved to be extremely useful for the interpretation of this high amplitude anomaly (Fig. 6). A time slice at $0.7 \mathrm{~ms}$ TWT (ca. $0.5 \mathrm{~m}$ ) beneath the bed illustrates the occurrence of a higher amplitude zone with a distinct ovate plan form coincident with the wreck location (Fig. 6a). Further, a zone of very high amplitudes can be distinguished within this clearly delineated area. This zone of very high amplitudes has shifted towards the left of the area on the deeper time slice at $1 \mathrm{~ms}$ TWT (ca. $0.8 \mathrm{~m}$ ), indicating that this is an event dipping towards the south-west (Fig. 6b). The deeper the time slice is situated beneath the riverbed, the smaller the ovate shape becomes. On the time slices beneath the anomaly, i.e. in the acoustic blanking zone, (e.g. $2.7 \mathrm{~ms}$ TWT; c. $2.0 \mathrm{~m}$ ), the high amplitudes have disappeared from the shipwreck zone altogether (Fig. 6c).

\subsection{Target characterisation}

Published work [17,18] on the acoustic properties of archaeological wood and, in particular oak, which was the dominant medieval boat building material, demon- strated that large, negative reflection coefficients are characteristic of degraded oak buried in fine grained sediments. Therefore, to test the hypothesis that the high
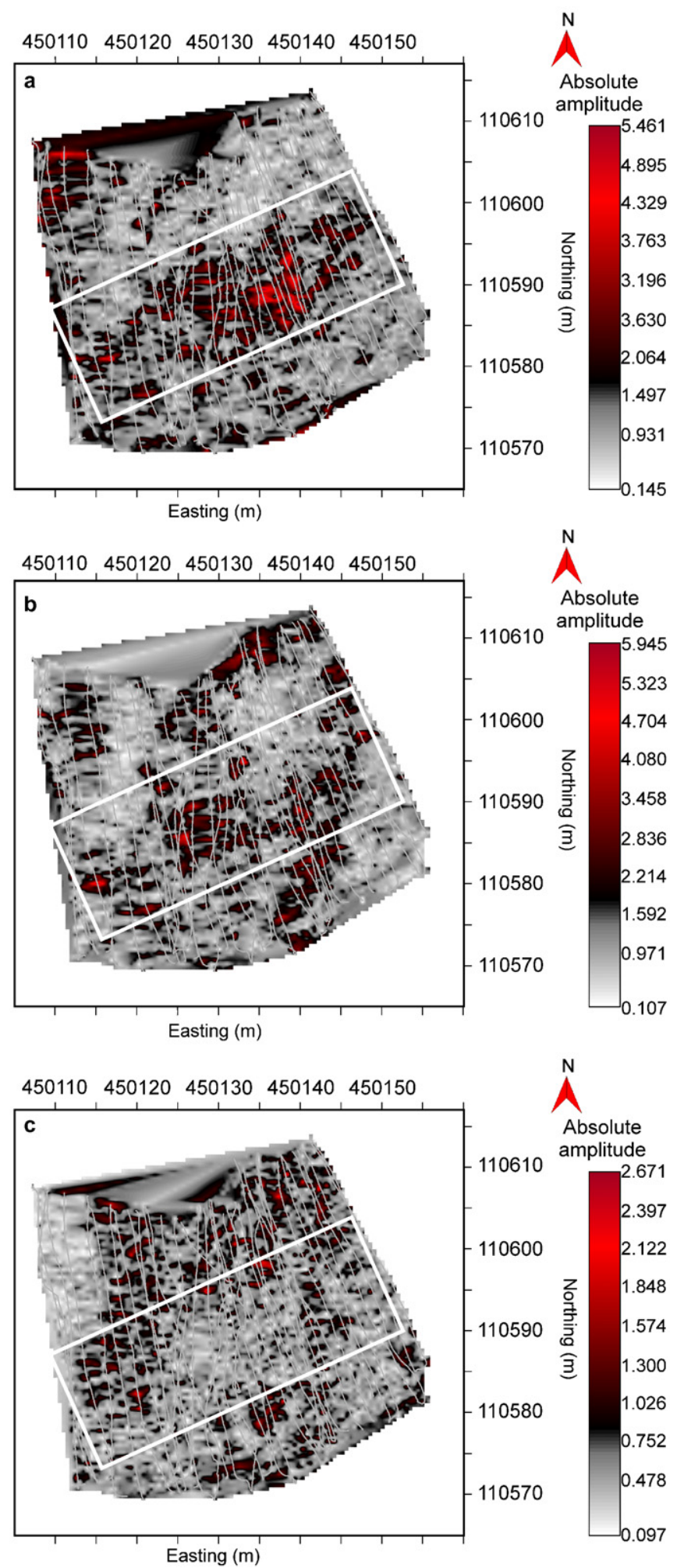

Fig. 6. Amplitude maps (a) $0.7 \mathrm{~ms}$ TWT, (b) $1.0 \mathrm{~ms}$ TWT and (c) $2.7 \mathrm{~ms}$ TWT beneath the riverbed. The colour bar represents absolute amplitudes of the correlated, processed data. Square white box indicates area of exposed timbers. (For interpretation of the references to colour in this figure legend, the reader is referred to the web version of this article.) 
amplitude anomaly, which is located within the shipwreck zone, is associated with the buried timbers of the Grace $\mathrm{Dieu}$, the reflection coefficients for two time slices were calculated. Firstly, at a depth of $0.7 \mathrm{~ms}$ TWT (ca. $0.5 \mathrm{~m}$ ) below the riverbed, where the ovate plan shape and a zone of very high amplitude reflectors were evident from the amplitude maps, and secondly, at $2.7 \mathrm{~ms}$ TWT (ca. $2.0 \mathrm{~m}$ ) below the riverbed, effectively beneath the remains of the vessel's hull.

As outlined in Appendix A, the first step in calculating the reflection coefficient is to derive the calibration factor from the amplitudes and TWT of both the riverbed and the first multiple reflectors. In very shallow water, this first multiple is situated close to the riverbed. It was observed from the acoustic Chirp data that there is often an interaction between this multiple and deeper reflectors. This makes it hard to pick the multiple and results in amplitude values which are the combination of the amplitude of the multiple and the amplitude of the deeper events. Therefore, only two sections of two Chirp lines (lines 2 and 3 ) were used to calculate the calibration factor (Figs. $7 \mathrm{a}$ and $\mathrm{b}$ ). In these most easterly located lines, the seabed and first multiple are represented by bright reflectors, related to higher amplitudes associated with coarser sediments towards the river margin. Using these sections made it easier to pick the riverbed and its multiple. An average value of $5.02 \times 10^{6}$ was calculated for the calibration factor and the histogram for the calibration factor results showed a large data spread with a major peak around $5 \times 10^{6}$ (Fig. 7c).

The reflection coefficients of the time slices were then calculated using expression (1) and the resulting contour maps (Figs. 8b and d) show a strong correlation with the amplitude maps of the processed data (Figs. 8a and c); i.e. areas with high amplitudes in the enveloped processed data correspond to areas with high reflection coefficients in the raw correlated data.

For the time slice at $0.7 \mathrm{~ms}$ TWT below the seabed, the average absolute reflection coefficient for the area of ovate planform is $|0.32|$ for those lines where bright reflectors were clearly present on the Chirp cross sections. On the same time slice, an area within the shipwreck site with very high amplitudes was targeted (broken line in Fig. 8b). This zone is characterised by an even higher absolute reflection coefficient of $|0.46|$. Further analyses of the change in reflection coefficients for separate lines (Fig. 9, Table 1) illustrate the difference between values in the shipwreck area and values for the sediments surrounding the remains of the vessel. For the time slice at $0.7 \mathrm{~ms}$ TWT below the riverbed (Figs. $9 \mathrm{a}, \mathrm{c}, \mathrm{e})$, reflection coefficients are much higher in the shipwreck zone $(|0.27|-|0.41|)$ compared to the surrounding sediments $(|0.16|-|0.20|)$. Therefore, as predicted, the modulus of the reflection coefficients associated with the main structure of the wreck are atypical for sediment features found within an inter-tidal riverine environment, which are normally smaller than $|0.2|[19]$. It should be noted that all calculated reflection coefficients are likely to be an underestimation of the real value (e.g. [17,20]).

Although this approach is able to establish a robust modulus for the reflection coefficient, establishing the polarity of the coefficient is more difficult. Shifts in the polarity between traces are a known feature of Chirp data. Bull et al. [17] demonstrated that these are the consequence of bioturbation and small-scale lateral changes in the stra-

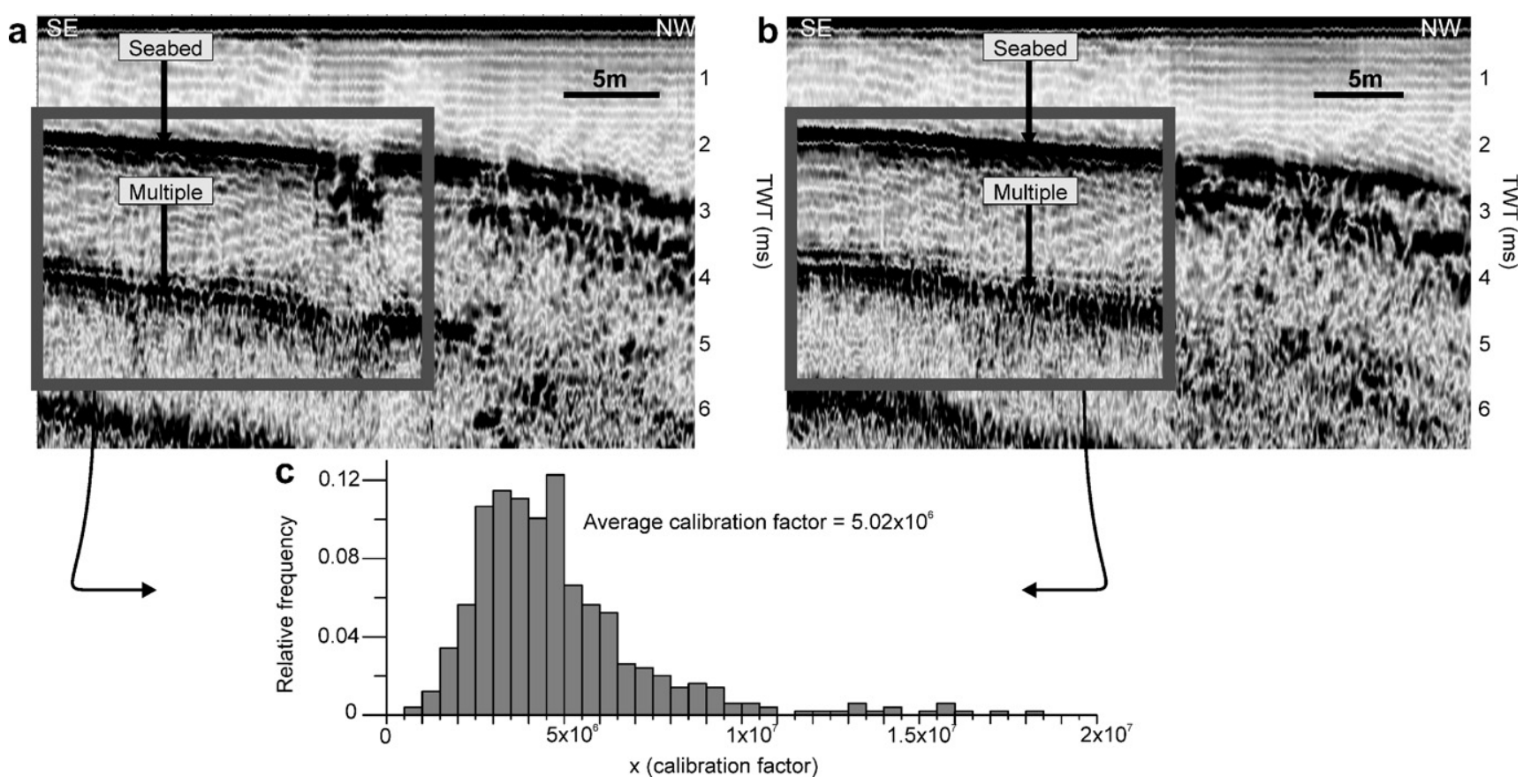

Fig. 7. ( $\mathrm{a}$ and $\mathrm{b}$ ) Sections of line 2 and line 3 used to calculate the calibration factor $x$. (c) Histogram for the calibration factor. 


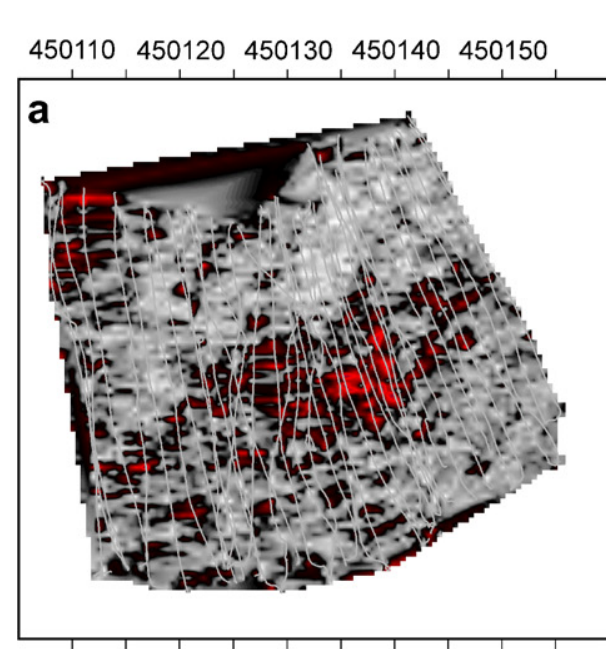

Easting $(m)$

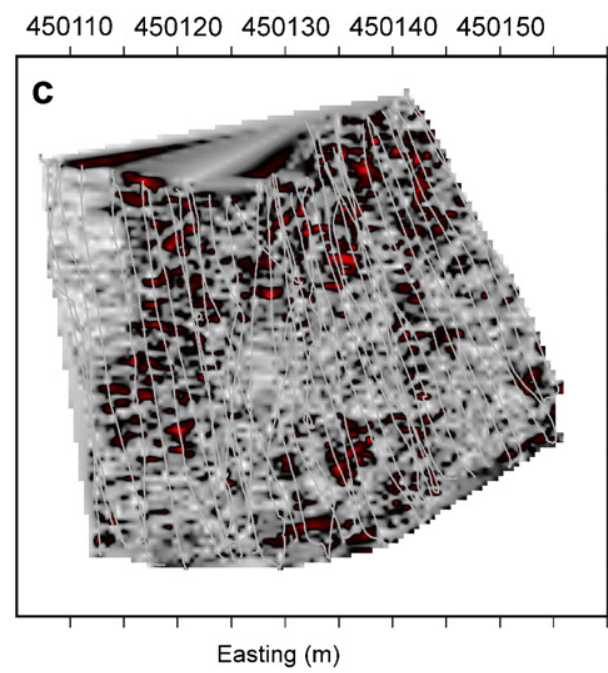

$\mathrm{N}$

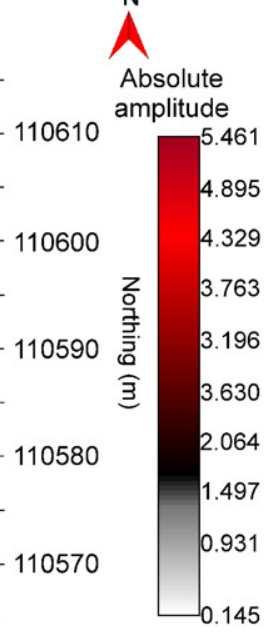

N

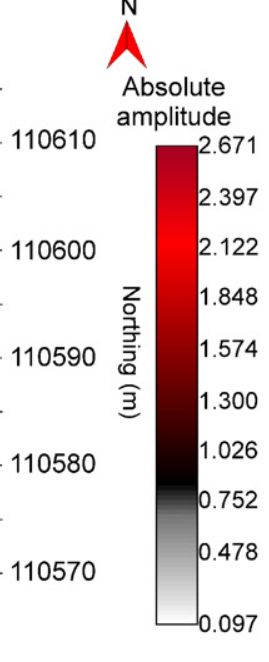

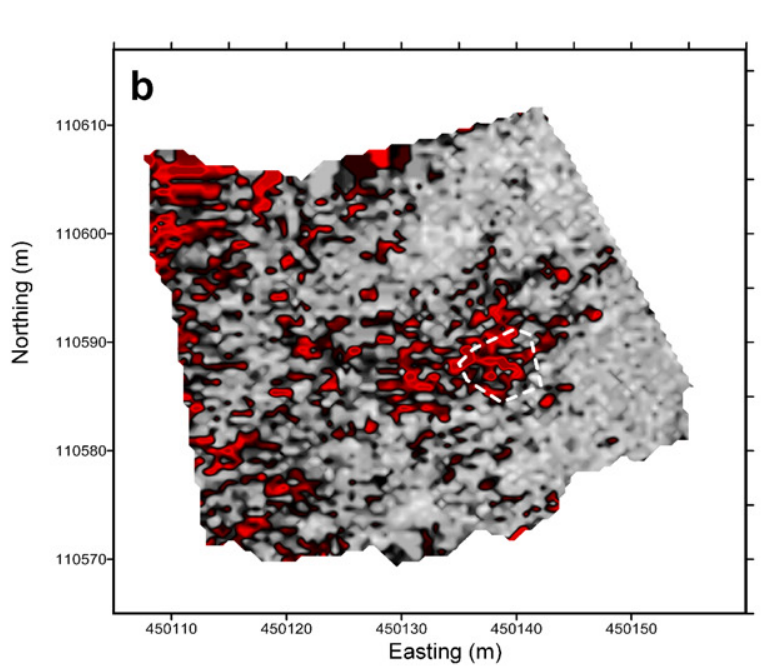
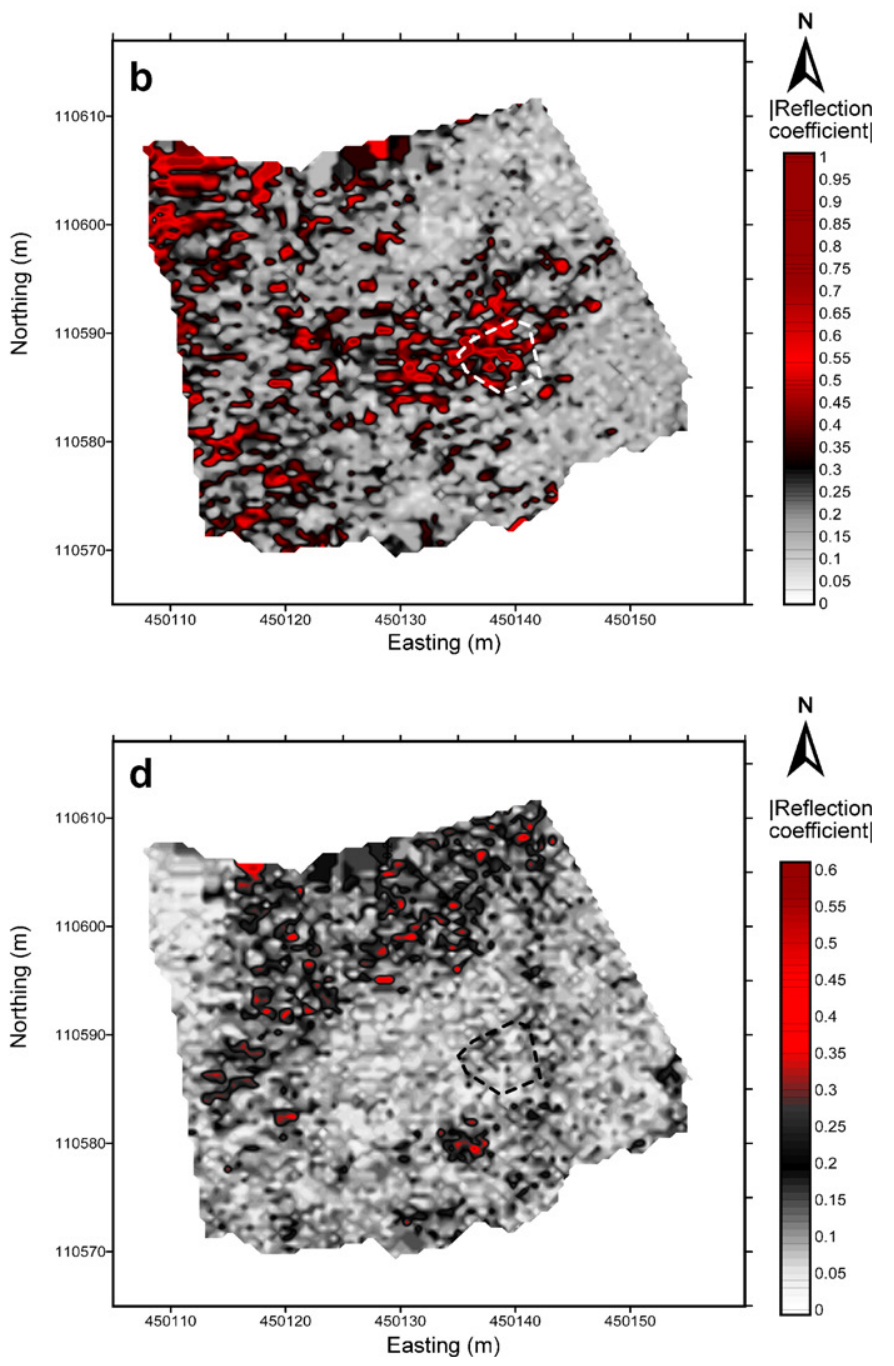

Fig. 8. (a) Amplitude map and (b) absolute reflection coefficient for a time slice $0.7 \mathrm{~ms}$ TWT beneath the riverbed; (c) amplitude map and (d) absolute reflection coefficient for a time slice $2.7 \mathrm{~ms}$ TWT beneath the riverbed. Delineated zones refer to areas described in the text.

tigraphy. For the high reflection coefficients associated with the wreck area, over $50 \%$ of the measurements are associated with negative polarities. This tendency towards negative reflection coefficients in the shipwreck area is in line with previous studies $[6,17,18]$.

The interpretation of this data can be taken one stage further through comparison with the work of Arnott et al. [18] who describe a method to actually estimate the degradation state of buried archaeological wood from the reflection coefficients. This work shows that reflection coefficients for radial and tangential oak samples (the structural directions associated with ship's planking) show a strong linear relationship with the conventional density $\left(\rho_{\mathrm{c}}\right)$ of wood (conventional density being an established proxy for the degradation state of archaeological wood). For oak buried in inter-tidal sediments, with an acoustic velocity of $1517 \mathrm{~m} / \mathrm{s}$ and a mean grain size of $4.7 \phi$, their regression relationship, with the corresponding correlation coefficient $r^{2}$, can be written as:
$R C=0.0012 \rho_{\mathrm{c}}-0.6181$

for the tangential direction $\left(r^{2}=0.9008\right)$,

$R C=0.0013 \rho_{\mathrm{c}}-0.6754$

for the radial direction $\left(r^{2}=0.9205\right)$.

These relationships suggest that the large, negative, reflection coefficients $(R C)$ calculated for the Grace Dieu site ( -0.27 to -0.41$)$ correspond to a conventional density of $173-290 \mathrm{~kg} / \mathrm{m}^{3}$ for the tangential direction and a conventional density of $204-312 \mathrm{~kg} / \mathrm{m}^{3}$ for the radial direction. This suggests that the buried oak timbers are heavily degraded as the typical range of densities varies from $580 \mathrm{~kg} / \mathrm{m}^{3}$ for undegraded oak to $280 \mathrm{~kg} / \mathrm{m}^{3}$ for heavily degraded oak [18]. Such information is critical to the excavation and preservation strategies of archaeologists and conservators. It should be noted that if the reflection coefficient was positive, then the same modulus values would give a conventional density that ranges between $727 \mathrm{~kg} /$ 
$\mathrm{m}^{3}$ and $857 \mathrm{~kg} / \mathrm{m}^{3}$. This is a totally unrealistic value since fresh, undegraded oak has a conventional density of $580 \mathrm{~kg} / \mathrm{m}^{3}$. This further supports the idea that the reflection coefficient, related to the timbers of the Grace Dieu, should have a negative polarity.

Timeslice $0.7 \mathrm{~ms}$ TWT
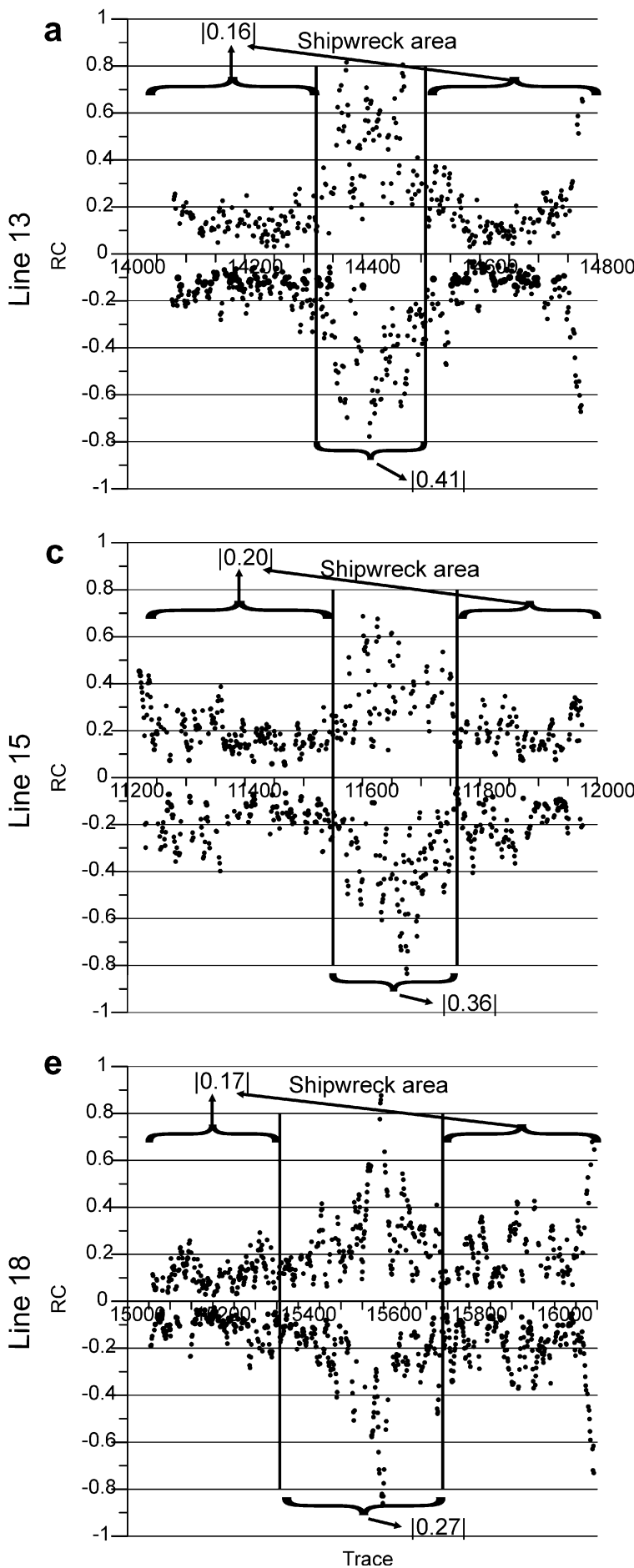

Therefore, the results obtained from the reflection coefficient calculations support the interpretation that the high amplitudes forming the ovate plan shape on the amplitude maps are created by the marginal timbers of the hull of the Grace Dieu. The even higher amplitude area within this
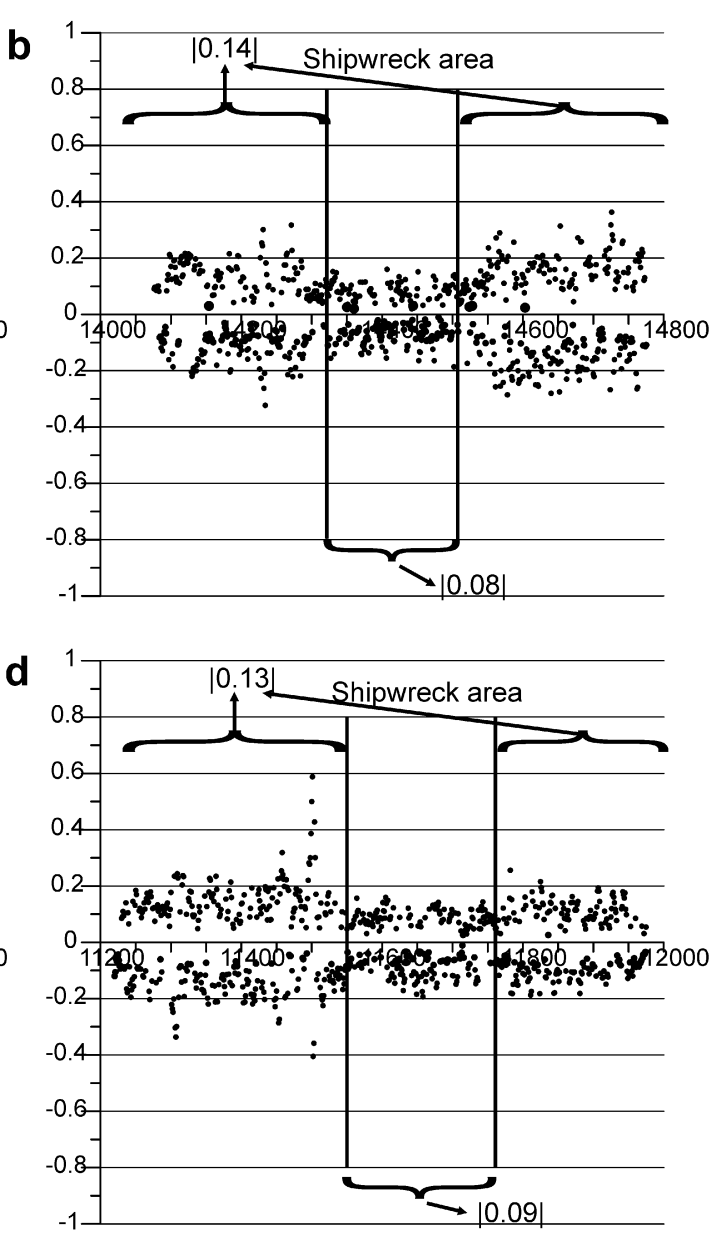

f

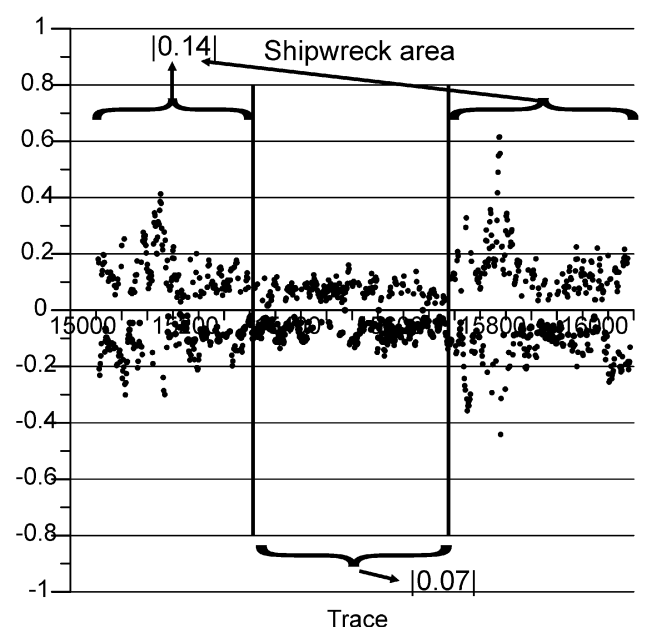

Fig. 9. Reflection coefficient values $(R C)$ for three individual lines (line 13, 15 and 18; see Fig. 4), for a time slice 0.7 ms TWT (through the anomaly) and $2.7 \mathrm{~ms}$ TWT (in the acoustic blanking zone) beneath the riverbed. 
Table 1

Absolute reflection coefficients $(R C)$ and polarity for three Chirp profiles acquired over the Grace Dieu wreck site

\begin{tabular}{|c|c|c|c|c|}
\hline & \multicolumn{2}{|c|}{ Surrounding sediments } & \multicolumn{2}{|c|}{ Shipwreck area } \\
\hline & $R C$ & $\%$ Negative & $R C$ & $\%$ Negative \\
\hline \multicolumn{5}{|l|}{ Line 13} \\
\hline $0.7 \mathrm{~ms}$ TWT & $|0.16|$ & 51 & $|0.41|$ & 54 \\
\hline $2.7 \mathrm{~ms}$ TWT & $|0.14|$ & 47 & $|0.08|$ & 48 \\
\hline \multicolumn{5}{|l|}{ Line 15} \\
\hline $0.7 \mathrm{~ms}$ TWT & $|0.20|$ & 45 & $|0.36|$ & 59 \\
\hline $2.7 \mathrm{~ms}$ TWT & $|0.13|$ & 50 & $|0.09|$ & 48 \\
\hline \multicolumn{5}{|l|}{ Line 18} \\
\hline $0.7 \mathrm{~ms}$ TWT & $|0.17|$ & 51 & $|0.27|$ & 47 \\
\hline $2.7 \mathrm{~ms}$ TWT & $|0.14|$ & 49 & $|0.07|$ & 53 \\
\hline
\end{tabular}

zone is interpreted as representing a horizon of timbers/ planking within the vessel's remaining hull. As demonstrated above, this horizon of, possibly collapsed, timbers dips towards the south-west. Furthermore, this result is in correspondence with probe test findings [11], indicating the occurrence of buried timbers at a depth of ca. $0.5 \mathrm{~m}$ beneath the riverbed.

Finally, the reflection coefficient was calculated for a time slice below the ship $(2.7 \mathrm{~ms}$ TWT beneath the riverbed), within the acoustic blanking zone (broken line Fig. 8d). In contrast to the high reflection coefficients found at $0.7 \mathrm{~ms}$ TWT beneath the riverbed, much lower values of $|0.09|$ were computed for the $2.7 \mathrm{~ms}$ TWT time slice. Reflection coefficient calculations for individual lines at $2.7 \mathrm{~ms}$ TWT below the riverbed (Fig. 9b, d, f; Table 1) show a noticeable drop within the shipwreck zone $(|0.07|-|0.09|)$ compared to the surrounding sediments $(|0.13|-|0.14|)$. The very low values for the reflection coefficients within the shipwreck zone, which are a third to a quarter of the values of the overlying wreck reflectors, confirm the idea of an acoustic blanking zone beneath the shipwreck.
The presence of such a significant drop in energy at depth beneath the wreck is also supported by laboratory measurements, which showed that the typical average attenuation coefficients for saturated oak are at least an order of magnitude higher than for typical sediment attenuation coefficients [21]. Hence, only a limited amount of energy should be able to penetrate a wooden object buried within sediments, creating a blanking zone beneath it. Therefore, the detection of such an acoustic blanking zone has high potential as a visual and quantitative aid for future shipwreck detection. Further research into the quantitative characterisation of this acoustic property using seismic reflection data is currently underway.

\subsection{Data interpretation and $3 D$ reconstruction}

Currently, full 3D shipwreck reconstructions are the end result of many months or years of archaeological excavation and detailed logging of timbers, combined with information obtained from extensive historical research. Therefore, the current state of the art in reconstructing sunken shipwrecks requires that such sites are exposed (e.g. [22]). Because the remains of the Grace Dieu are buried in inter-tidal mud and since no ship plans were used in the 15th century, and therefore, accurate historical information regarding the ship's exact dimensions and shape is unavailable, original size and form of this unique structure have remained defined only by partial and inexact dimensions noted at the time. However, it was possible to redress this situation by using the acquired acoustic data.

In the first instance, an isopach map, i.e. a map that shows the depth of burial of the feature under the riverbed, was created using the following procedure. With the help of the results from the amplitude maps, the base of the high amplitude anomaly (interpreted to be the inner planking of the vessel Grace Dieu) was picked manually on each seismic section. The interpolated surface from these picks was

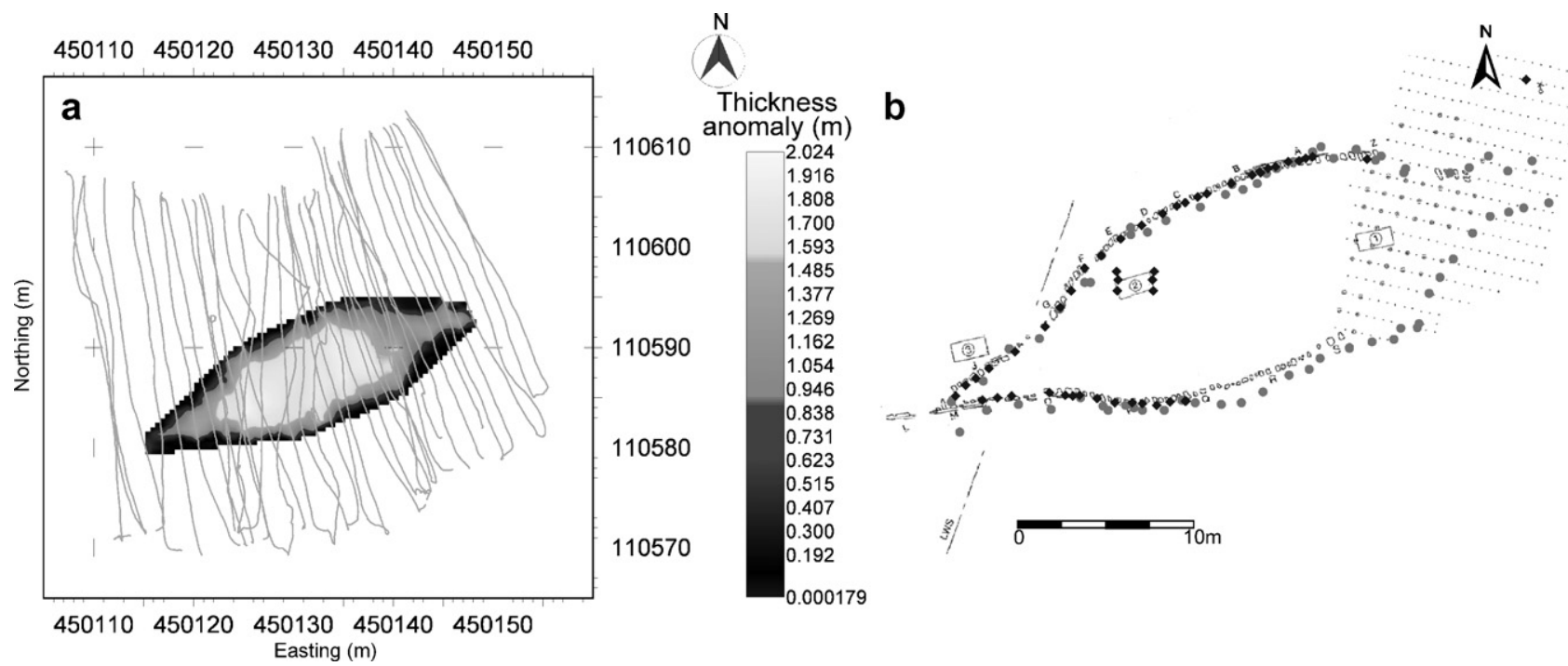

Fig. 10. (a) Isopach map showing the thickness of the anomaly (in metres). (b) Comparison of the Chirp data (@) and terrestrial RTK data ( ). 

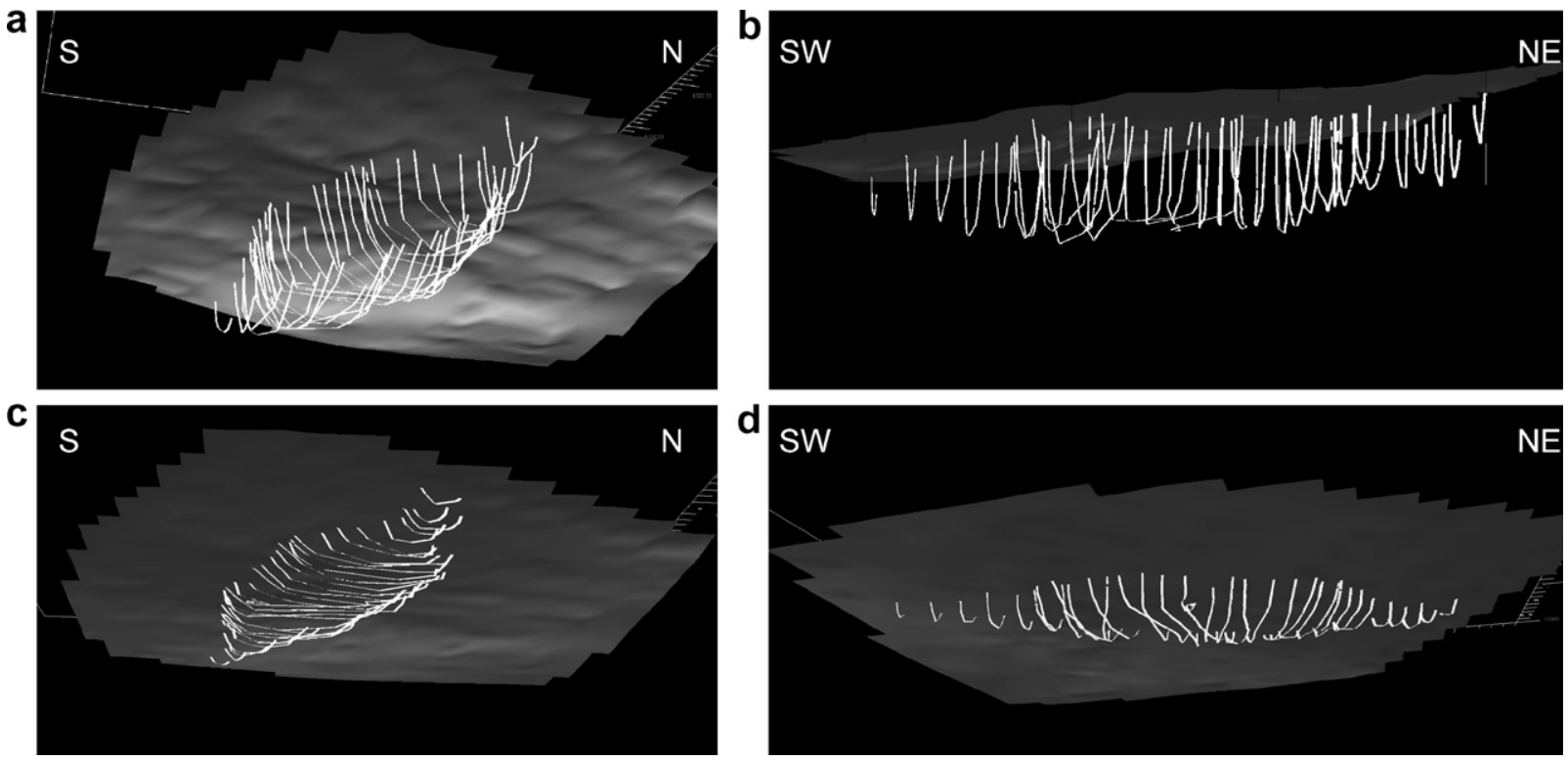

Fig. 11. Pseudo-3D reconstruction of the buried remains of the hull of the Grace Dieu (a and b) with a vertical exaggeration (4×); and (c and d) with a 1:1:1 scale.

then subtracted from the interpolated riverbed surface to create an isopach (Fig. 10a). In the next stage, the picks on the $2 \mathrm{D}$ sections were used to create a pseudo-3D visualisation of the hull remains of the Grace Dieu (Fig. 11). These vertically exaggerated $(4 \times)$ representations show how the remaining hull dips towards the south-west beneath a north-westward sloping riverbed (Figs. 11a and b). A more realistic view is given by the 1:1 reconstruction (Figs. 11c and d).

These two modes of visualisation both show a well defined and pronounced longitudinal and lateral axial (keel) symmetry with maximum dimensions of $35.4 \mathrm{~m} \times 11.4 \mathrm{~m}$ and a maximum burial depth of $2 \mathrm{~m}$. Furthermore, it should be noted that this feature has steep sides (futtocks) just beneath the riverbed (between $0 \mathrm{~m}$ and $1.5 \mathrm{~m}$ beneath the riverbed) with very flat floor timbers at its deepest point (between $1.5 \mathrm{~m}$ and $2 \mathrm{~m}$ beneath the riverbed).

Moreover, the outline derived from the interpreted Chirp data shows good correlation with the original site plan (Fig. 10b), with a maximum recorded offset between the marine DGPS derived picks and terrestrial RTK dataset of only $0.7 \mathrm{~m}$ (an exceptional result considering the positional accuracy of the DGPS system). The dimensions derived from the isopach map also show good correspondence with the limited historical [11] and archaeological [23] evidence available (Table 2).

Table 2

Comparison of the Grace Dieu's dimensions from historical, archaeological and geophysical evidence

\begin{tabular}{llll}
\hline & Albizzi [10] & Anderson [23] & This study \\
\hline Length & $67 \mathrm{~m}$ (main deck) & $38 \mathrm{~m}$ buried remains & $35.4 \mathrm{~m}$ buried remains \\
Breadth & $\begin{array}{l}15.4 \mathrm{~m} \\
\text { (upper deck) }\end{array}$ & $11.3 \mathrm{~m}$ buried remains & $11.4 \mathrm{~m}$ buried remains \\
& & & \\
\hline
\end{tabular}

Although the degree of accuracy obtained from acoustic data (with decimetric vertical and metric horizontal resolution) is less than what divers can record manually from exposed shipwrecks, it is hoped that the Chirp data acquired over the Grace Dieu site can be used to portray a faired version of the original hull of this vessel (i.e. by smoothing the ship lines in three planes). At the very least, it will aid archaeologists to optimise excavation and minimise its impact.

\section{Conclusion}

Buried object detection in shallow-water environments with standard sonar equipment is often unsuccessful unless traditional surveying methods are adapted. In the case of this archaeological study of an inter-tidal zone site, high quality data were collected by ensuring that a monostatic system was used and that the creation of bubble noise was avoided.

The fact that a standard high-resolution Chirp system was used and that two hours of surveying over the known site, during which two divers pushed the source over the wreck in a controlled manner, provided sufficient coverage, means that this technique is much more cost-effective than extensive excavation. Even if excavation were planned, this type of acoustic dataset can help maritime archaeologists to plan and optimize intrusive investigations.

As a result of the good data coverage, all three initial aims were fulfilled:

(1) The buried wooden hull of the Grace Dieu was imaged successfully as an assemblage of high amplitude reflectors, associated with a blanking zone and truncating the local stratigraphy. 
(2) A method was developed to calculate reflection coefficients for normal incidence reflection data acquired in shallow water. Atypically large and predominantly negative values for the reflection coefficient were interpreted as evidence for degraded oak buried in fine grained sediments. The strong high amplitude reflectors within the shipwreck area are believed to relate to a horizon of incoherent timbers, dipping towards the south-west. Using the reflection properties of the buried wood demonstrated that the oak timbers are heavily degraded.

(3) The combination of acoustic vertical sections, horizontal amplitude maps and identification of the material properties, made it possible to pick the outline of the remaining hull both in plan view and in $2 \mathrm{D}$ seismic sections, ultimately resulting in a pseudo-3D reconstruction. This reconstruction identified the maximum dimensions and true plan form of this vessel, supporting the assertion that the Grace Dieu was the most significant naval design for over two centuries.

In addition, the association of an acoustic blanking zone beneath the shipwreck demonstrates the highly reflective and attenuating nature of degraded wood. This feature could become a major aid for future buried shipwreck detection although more research is needed in the quantitative characterisation and implications of this masking area.

The results of the acoustic data have been tested against archaeological and terrestrial RTK-GPS data. The good agreement between datasets and the detail extracted from the acoustic data shows the potential to detect a wide variety of buried objects accurately in the complex environment of the shallow inter-tidal zone.

\section{Acknowledgements}

This project is part of a Ph.D. study, funded by the School of Ocean and Earth Science (University of Southampton) and the Challenger Division (National Oceanography Centre, Southampton). Thanks to J. Davis for technical support and to Dr. D. Wheatley for the RTK-survey and -data processing. Special thanks to all the 'courageous' divers who were willing to brave the freezing water during the coldest week of the year! We are also grateful to the two anonymous reviewers who helped to improve this paper.

\section{Appendix A}

The reflection coefficient $(R C)$, a measure which can be related to the physical properties of the materials, is the ratio of the amplitude of the reflected wave $\left(A_{\mathrm{r}}\right)$ and the amplitude of the incident wave $\left(A_{\mathrm{i}}\right)$ :

$R C_{12}=\frac{A_{\mathrm{r}}}{A_{\mathrm{i}}}$.
Warner states that the absolute amplitude of the primary (seabed or riverbed) reflection $A_{\mathrm{p}}$ is given by [14]:

$A_{\mathrm{p}}=\frac{R C_{\mathrm{p}} \cdot x}{d}$,

where $R C_{\mathrm{p}}$ is the unknown reflection coefficient of the sea/ riverbed, $d$ is a factor due to geometric spreading, and $x$ is a calibration factor. Similarly, the amplitude $A_{\mathrm{m}}$ of the first multiple can be written as [14]:

$A_{\mathrm{m}}=\frac{R C_{\mathrm{p}}^{2} \cdot x}{2 d}$.

Since the energy of an expanding spherical pressure wave decreases as $1 / r_{\mathrm{s}}^{2}$ (inverse square law, with $r_{\mathrm{s}}$ the radius of the sphere) and since energy is proportional to amplitude squared, an inverse square law for energy translates to a $1 / r_{\mathrm{s}}$ decay law for amplitude, or:

$A \sim \frac{1}{r_{\mathrm{s}}}\left(=\frac{1}{d}\right)$,
$A \sim \frac{1}{v \cdot(T W T / 2)}$.

Substituting (A.4b) in (A.2) and (A.3) gives:

$A_{\mathrm{p}}=\frac{R C_{\mathrm{p}} \cdot x}{v_{\mathrm{w}} \cdot\left(T W T_{\mathrm{p}} / 2\right)}$,

and

$A_{\mathrm{m}}=\frac{R C_{\mathrm{p}}^{2} \cdot x}{2 v_{\mathrm{w}} \cdot\left(T W T_{\mathrm{p}} / 2\right)}=\frac{R C_{\mathrm{p}}^{2} \cdot x}{v_{\mathrm{w}} \cdot\left(T W T_{\mathrm{m}} / 2\right)}$,

with $v_{\mathrm{w}}$ the velocity of sound in water, $T W T_{\mathrm{p}}$ the two-waytravel time to the primary sea/riverbed reflector and $T W T_{\mathrm{m}}$ the two-way-travel time to the first multiple.

From (A.5):

$R C_{\mathrm{p}}=\frac{A_{\mathrm{p}} \cdot v_{\mathrm{w}} \cdot\left(T W T_{\mathrm{p}} / 2\right)}{x}$.

From (A.6) and (A.7):

$A_{\mathrm{m}}=R C_{\mathrm{p}} \cdot \frac{R C_{\mathrm{p}} \cdot x}{v_{\mathrm{w}} \cdot\left(T W T_{\mathrm{m}} / 2\right)}$,

$A_{\mathrm{m}}=\frac{A_{\mathrm{p}} \cdot v_{\mathrm{w}} \cdot\left(T W T_{\mathrm{p}} / 2\right)}{x} \cdot \frac{R C_{\mathrm{p}} \cdot x}{v_{\mathrm{w}} \cdot\left(T W T_{\mathrm{m}} / 2\right)}$.

So, the absolute reflection coefficient of the seabed can be written as (from (A.8b)):

$R C_{\mathrm{p}}=\left|\frac{A_{\mathrm{m}}}{A_{\mathrm{p}}}\right| \cdot \frac{T W T_{\mathrm{m}}}{T W T_{\mathrm{p}}}$.

From (A.2) and (A.9), the calibration factor can be determined as:

$x=\left|\frac{A_{\mathrm{p}} \cdot d}{R C_{\mathrm{p}}}\right|$,

$x=\left|\frac{A_{\mathrm{p}} \cdot v_{\mathrm{w}} \cdot\left(T W T_{\mathrm{p}} / 2\right)}{R C_{\mathrm{p}}}\right|$. 
Now that the calibration factor is known, the reflection coefficient of any deep reflector $R C_{\mathrm{DR}}$ can be calculated, since the amplitude of a deeper reflector $A_{\mathrm{DR}}$ can be written as:

$A_{\mathrm{DR}}=\frac{R C_{\mathrm{DR}}}{v_{\mathrm{w} \_\mathrm{DR}} \cdot\left(T W T_{\mathrm{DR}} / 2\right)} \cdot x$,

with $v_{\mathrm{w} \_\mathrm{DR}}$ the combination of the velocity of sound through water and the velocity of sound through the sedimentary layer (i.e. this will depend on the depth of the water columns and depth of burial) and $T W T_{\mathrm{DR}}$ the twoway-travel time to the deeper reflector. Hence, the reflection coefficient of any deeper reflector is:

$$
\begin{aligned}
& R_{\mathrm{DR}}=\frac{A_{\mathrm{DR}} \cdot v_{\mathrm{w}-\mathrm{DR}} \cdot\left(T W T_{\mathrm{DR}} / 2\right)}{x}, \\
& R_{\mathrm{DR}}=\frac{A_{\mathrm{DR}} \cdot\left[v_{\mathrm{w}} \cdot\left(T W T_{\mathrm{p}} / 2\right)+\overline{v_{\mathrm{DR}}} \cdot\left(T W T_{\mathrm{DR}}-T W T_{\mathrm{p}}\right) / 2\right]}{x},
\end{aligned}
$$

with $\overline{v_{\mathrm{DR}}}$ the interval velocity or velocity of sound in the sediments. The sign of the reflection coefficient is determined by the polarity of the reflector.

\section{References}

[1] Smith AD, Taymaz T, Oktay F, Yuce H, Alpar B, Bascaran H, et al. High-resolution seismic profiling in the Sea of Marmara (Northwest Turkey) - Late Quaternary sedimentation and sea-level changes. Geol Soc Am Bull 1995;107(2):923-36.

[2] Smith GF, Bruce DG, Roach EB. Remote acoustic habitat assessment techniques used to characterize the quality and extent of Oyster Bottom in the Chesapeake Bay. Mar Geodesy 2001;24:171-89.

[3] Lenham JW, McDonald R, Miller S, Reynolds JM. Integrated seismic investigations across the Mersey Estuary, Halton District, UK. Q J Eng Geol Hydrogeol 2005;38:7-22.

[4] Quinn R, Bull JM, Dix JK. Buried scour marks as indicators of palaeo-current direction at the Mary Rose wreck site. Mar Geol 1997;140(3-4):405-13.

[5] Mathys M, Thiessen O, Theilen F, Schmidt M. Seismic characterization of gas rich near surface sediments in the Arkara Basin, Baltic Sea. Mar Geophys Res 2005;26(2-4):207-24.

[6] Quinn R, Adams JR, Bull JM, Dix JK. The Invincible (1758) site - an integrated geophysical assessment. Int J Nautical Archaeol 1998;27: 126-38.
[7] Mindell DA, Bingham BA. High-frequency, narrow-beam sub bottom profilers for archaeological applications. In: Oceans'01 MTS/IEEE conference proceedings, Honolulu, Hawai; 2001. p. 2115-23.

[8] Schock SG, Tellier A, Wulf J, Sara J, Ericksen M. Buried object scanning sonar. IEEE J Oceanic Eng 2001;26(4):677-89.

[9] Amate M, Hétet A, Guyonic S, Legris M, Bellec R, Maussang F, et al. Buried mines detection and classification: advanced technologies and signal processing. In: Oceans'05 Europe IEEE/OES conference proceedings, Brest, France; 2005.

[10] Friel I. Henry V's Grace Dieu and the wreck in the River Hamble near Bursledon, Hampshire. Int J Nautical Archaeol 1993;22(1):3-19.

[11] Clarke R, Dean M, Hutchinson G, McGrail S, Squirrell J. Recent work on the R. Hamble wreck near Bursledon, Hampshire. Int $\mathbf{J}$ Nautical Archaeol 1993;22(1):21-44.

[12] Schock SG, Leblanc LR, Panda S. Spatial and temporal pulse design considerations for a marine sediment classification sonar. IEEE $\mathbf{J}$ Oceanic Eng 1994;19(3):406-15.

[13] Ziomek LJ. Underwater acoustics, a linear system theory approach. Orlando: Academic Press; 1985.

[14] Warner M. Absolute reflection coefficients from deep seismic reflections. Tectonophysics 1990;173:15-23.

[15] Lovett JR. Merged seawater sound-speed equations. J Acoust Soc Am 1978;63(6):1713-8.

[16] Robb GBN, Dix JK, Best AI, Bull JM, Leighton TG, White PR, et al. The compressional wave and physical properties of inter-tidal marine sediments. In: Proceedings of the international conference "underwater acoustic measurements: technologies \& results", Heraklion, Crete, Greece; 2005.

[17] Bull JM, Quinn R, Dix JK. Reflection coefficient calculation from marine high resolution seismic reflection (Chirp) data and application to an archaeological case study. Mar Geophys Res 1998;20:1-11.

[18] Arnott SHL, Dix JK, Best AI, Gregory DJ. Imaging of buried archaeological materials: the reflection properties of archaeological wood. Mar Geophys Res 2005;26(2-4):135-44.

[19] Kearey P, Brooks M. An introduction to geophysical exploration. 2nd ed. Oxford: Blackwell Science; 1991.

[20] Kuperman WA. Coherent component of specular reflection and transmission at a randomly rough two-fluid interface. J Acoust Soc Am 1975;58(2):365-70.

[21] Dix JK. Acoustic characterization of archaeological materials in the marine environment: developments and challenges. In: Satchell J, Palma P, editors. Managing the marine cultural heritage: defining, accessing and managing the resource (Council for British Archaeology Report 153); 2007.

[22] Ships AJ. Innovation and social change. Aspects of carvel shipbuilding in Northern Europe 1450-1850. PhD Thesis, Stockholm, University of Stockholm; 2003.

[23] Anderson RC. The Bursledon ship. Mariner's Mirror 1934;20:158-70. 